\section{Structure Elucidation of a New Antifungal Sterol Sulfate, Sch 575867, from a Deep-Water Marine Sponge (Family: Astroscleridae)}

\author{
Shu-Wei Yang, ${ }^{a, *}$ Tze-Ming Chan, ${ }^{a}$ Shirley A. Pomponi, ${ }^{b}$ \\ Guodong Chen, ${ }^{a}$ David Loebenberg, ${ }^{a}$ Amy Wright, \\ Mahesh Patel, ${ }^{a}$ Vincent Gullo ${ }^{a}$ \\ Birendra Pramanik and Min $\mathrm{CHU}^{\mathrm{a}}$ \\ ${ }^{\text {a }}$ Schering-Plough Research Institute, \\ 2015 Galloping Hill Road, Kenilworth, NJ 07033, USA \\ ${ }^{\mathrm{b}}$ Harbor Branch Oceanographic Institution, \\ 5600, U.S. 1 North, Fort Pierce, FL 34946, USA
}

(Received for publication September 30, 2002)

In the course of our continuing search for novel antimicrobial agents, a new sterol sulfate, Sch 575867 (1), was isolated and identified from a marine sponge (Family: Astroscleridae). In this paper, we describe the isolation and structure elucidation of 1 using high resolution ESMS and extensive NMR spectroscopic analysis.

The sponge was collected using the Johnson-Sea-Link I manned submersible at a depth of $375 \mathrm{ft}$ off Andros Island, Bahamas near Stafford creek. (Latitude: 24⒌ $550^{\prime} \mathrm{N}$; Longitude $77^{\circ} 53.3^{\prime} \mathrm{W}, 375$ feet). The sponge can not be identified to genus, but has been identified as belonging to the Family Astroscleridae (Demospongiae, Sclerospongiae, Ceratoporellidae). ${ }^{1)}$ It is described as a red-orange, rock hard, $15 \mathrm{~cm}$ spherical sponge, with a thin veneer of living tissue over an aragonite skeleton. The surface is porous and smooth, with $2 \mathrm{~cm}$ diameter mounds. A reference sample preserved in ethanol has been deposited in the Harbor Branch Oceanographic Museum (catalog number 003:00989, DBMR number 24-VIII-85-1-053) and is available for taxonomic evaluation.

Crude sponge sample $(\sim 100 \mathrm{~g})$ was diced and ground for three minutes in ethanol $(40 \mathrm{ml})$ three times. After the filtration and solvent removal in vacuum, the organic extract was fractionated on a column of polymeric resin, CG161 $(\sim 60 \mathrm{ml})$ to generate 6 fractions using stepwise gradient of aqueous acetonitrile (ACN) $(120 \mathrm{ml}$ of each $10 \%, 25 \%, 50 \%, 75 \%, 100 \% \mathrm{ACN}$, and $1: 1$ methanolEtOAc wash). All fractions were dried and yielded a total of $118 \mathrm{mg}$ of enriched material. Antifungal activity was observed in fraction 3 (45 mg, 50\% ACN elution). Fraction
3 was further fractionated on an HPLC semi-preparative ODS-A column (YMC, $120 \mathrm{~A}, \mathrm{~S}-7,2 \mathrm{~cm} \times 25 \mathrm{~cm}$ ). The column was eluted with a gradient of $\mathrm{ACN}-\mathrm{H}_{2} \mathrm{O}(3 \%$ to $40 \% \mathrm{ACN}$ in 40 minutes, and then $40 \%$ to $100 \% \mathrm{ACN}$ in another 40 minutes, $15 \mathrm{ml} /$ minute). A total of 100 fractions were collected (13 ml/fraction). Pure 1 (5 mg) was obtained at $48 \sim 49$ minutes as colorless gum.

From high-resolution negative ESMS, the molecular formula of 1 was established as $\mathrm{C}_{32} \mathrm{H}_{53} \mathrm{O}_{13} \mathrm{~S}_{3}$ (Found 741.2648; calcd. 741.2653 for $[\mathrm{M}-3 \mathrm{Na}+2 \mathrm{H}]^{-}, \Delta 0.78$ ppm) suggesting three sulfate groups in the molecule (performed on a PE Sciex QSTAR mass spectrometer; two internal standards, taurocholic acid and nitrazepan, were used in the negative ion ESI-HR-MS measurements). The structure of 1 was elucidated by extensive NMR data analysis. Thirty two carbons were observed in the ${ }^{13} \mathrm{C}$ NMR spectrum, suggesting a triterpene skeleton with two additional carbons. Highly overlapped proton signals in ${ }^{1} \mathrm{H}$ NMR can be interpreted and assigned to their adjacent carbons by HSQC analysis. The connectivity of protonated fragments were determined primarily by HSQC-TOCSY data (Table 1). Thus the fragments A, B, C, and D were established through two or three $\mathrm{H}-\mathrm{C}$ bond correlations (Figure 1). With the information of fragments A, C, and D, the entire ring skeleton was further determined by analysis of HMBC data with the following $\mathrm{H}-\mathrm{C}$ correlations: $\mathrm{H}_{3}-19$ $(\delta$ 1.41) to C-1 ( $\delta 38.0), \mathrm{C}-5$ ( $\delta 48.3), \mathrm{C}-9(\delta$ 146.4), and $\mathrm{C}-10 \cdot(\delta 39.5) ; \mathrm{H}_{3}-18(\delta$ 0.70) to $\mathrm{C}-12(\delta 38.4), \mathrm{C}-13(\delta$ $45.7), \mathrm{C}-14(\delta 48.2)$, and $\mathrm{C}-17(\delta 52.3) ; \mathrm{H}_{3}-32(\delta 0.81)$ to C-8 ( $\delta 41.5), \mathrm{C}-13(\delta 45.7), \mathrm{C}-14(\delta 48.2)$, and C-15 $(\delta$ 35.0) (see Figure 2).

Excluding the ring system and the fragments $\mathrm{B}$ and $\mathrm{C}$, a vinyl group ( $\delta 113.0 \mathrm{t}, \delta 150.9 \mathrm{~s}$ ), a methyl group ( $\delta 20.0$ q) and a quaternary carbon ( $\delta 45.7 \mathrm{~s}$ ) were to be assigned to the side chain. These groups can be connected based on

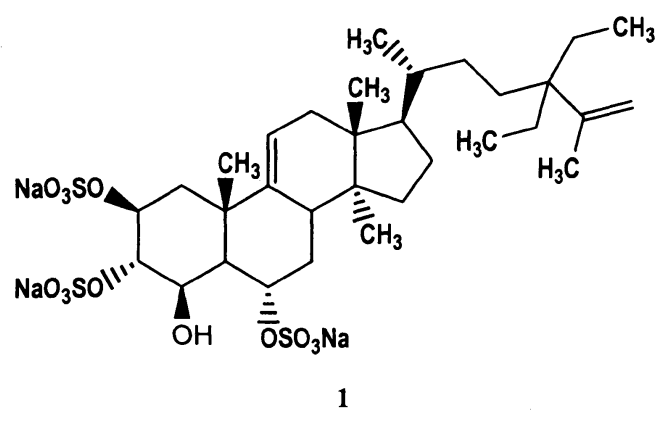


Table 1. NMR spectral data for compound 1 in $\mathrm{CD}_{3} \mathrm{OD}^{\mathrm{a}}$.

\begin{tabular}{|c|c|c|c|c|}
\hline $\mathrm{C} / \mathrm{H}$ no. & ${ }^{1} H(\delta)$ & ${ }^{13} \mathrm{C}(\delta)$ & $\begin{array}{l}\text { HSQC- } \\
\text { TOCSY } \\
\text { C No. }\end{array}$ & HMBC \\
\hline $1 \alpha$ & $1.85, \mathrm{dd}, J=14.5,4.0$ & $38.0 \mathrm{t}$ & 2 & \\
\hline $1 \beta$ & 2.28, , brd, $J=14.5$ & & & \\
\hline 2 & 4.93, brs & $76.1 \mathrm{~d}$ & 1,3 & \\
\hline 3 & $4.83, \mathrm{brs}$ & $76.8 \mathrm{~d}$ & 2,4 & \\
\hline 4 & $4.44, \mathrm{brs}$ & $68.6 \mathrm{~d}$ & 3,5 & $C-3, C-10$ \\
\hline 5 & $1.42, \mathrm{~m}$ & $48.3 d$ & 4,6 & \\
\hline 6 & $4.83, \mathrm{~m}$ & $76.3 d$ & 5,7 & \\
\hline $7 \alpha$ & $\begin{array}{l}1.55, \text { ddd, } J=12,12 \text {, } \\
12\end{array}$ & $35.6 \mathrm{t}$ & 6,8 & \\
\hline $7 \beta$ & $2.22, \mathrm{dt}, J=11,4.5$ & & & \\
\hline 8 & 2.48, brd, $J=13$ & $41.5 d$ & 7 & \\
\hline 9 & & $146.4 \mathrm{~s}$ & & \\
\hline 10 & & $39.5 \mathrm{~s}$ & & \\
\hline 11 & $5.35, d, J=5.5$ & $118.0 \mathrm{~d}$ & 12 & $C-8, C-10, C-12, C-13$ \\
\hline $12 \alpha$ & $2.11, d, J=18$ & $38.4 \mathrm{t}$ & 11 & \\
\hline $12 \beta$ & $1.96, \mathrm{dd}, J=18,6$ & & & \\
\hline 13 & & $45.7 \mathrm{~s}$ & & \\
\hline 14 & & $48.2 \mathrm{~s}$ & & \\
\hline \multirow[t]{2}{*}{15} & 1.37, m & $35.0 \mathrm{t}$ & 16 & \\
\hline & $1.46, m$ & & & \\
\hline \multirow[t]{2}{*}{16} & $1.30, m$ & $29.2 \mathrm{t}$ & 15,17 & \\
\hline & $1.91, m$ & & & \\
\hline 17 & $1.66, m$ & $52.3 d$ & 16,20 & \\
\hline 18 & $0.70, \mathrm{~s}$ & $15.1 \mathrm{q}$ & & $C-12, C-13, C-14, C-17$ \\
\hline 19 & $1.41, \mathrm{~s}$ & $25.5 q$ & & $C-1, C-5, C-9, C-10$ \\
\hline 20 & $1.34, m$ & $38.3 d$ & $\begin{array}{l}17,21 \\
22\end{array}$ & \\
\hline 21 & $0.92, d, J=6.5$ & $19.4 q$ & 20 & $C-17, C-20, C-22$ \\
\hline \multirow[t]{2}{*}{22} & $0.83, \mathrm{~m}$ & $31.0 \mathrm{t}$ & 20,23 & \\
\hline & $1.24, m$ & & & \\
\hline \multirow[t]{2}{*}{23} & $1.16, m$ & $31.4 \mathrm{t}$ & 22 & \\
\hline & $1.44, m$ & & & \\
\hline 24 & & $45.7 \mathrm{~s}$ & & \\
\hline 25 & & $150.9 \mathrm{~s}$ & & \\
\hline \multirow[t]{2}{*}{26} & $4.67, d, J=1.5$ & $113.0 \mathrm{t}$ & & C-24, C-25, C-27 \\
\hline & $4.90, t, J=1.5$ & & & \\
\hline 27 & $1.64, \mathrm{~s}$ & $20.0 q$ & & C-24, C-25, C-26 \\
\hline 28 & $1.37, \mathrm{~m}$ & $27.2 \mathrm{t}$ & 30 & C-23, C-24, C-25, C-29 \\
\hline 29 & $1.37, \mathrm{~m}$ & $27.0 \mathrm{t}$ & 31 & $C-23, C-24, C-25, C-28$ \\
\hline 30 & $0.68, t, J=7.5$ & $8.4 \mathrm{q}$ & 28 & $C-24, C-28$ \\
\hline 31 & $0.69, t, J=7.5$ & $8.4 \mathrm{q}$ & 29 & C-24, C-29 \\
\hline 32 & $0.81, \mathrm{~s}$ & $19.0 \mathrm{q}$ & & C-8, C-13, C-14, C-15 \\
\hline
\end{tabular}

${ }^{\mathrm{a}}$ Recorded on a Varian Unity $500 \mathrm{NMR}$ instrument at $500 \mathrm{MHz}$ for ${ }^{1} \mathrm{H}$ and 125

$\mathrm{MHz}$ for ${ }^{13} \mathrm{C}$, using standard Varian pulse sequence programs (VNMR Version

6.1 Software). $\delta$ in ppm; $J$ in $\mathrm{Hz}$. 
Fig. 1. Fragments A, B, C, and D determined by HSQC-TOCSY.

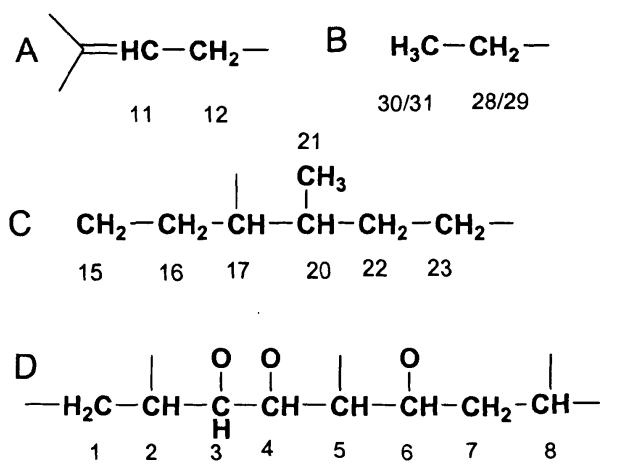

Fig. 2. Major HMBC correlations of $\mathbf{1}$.

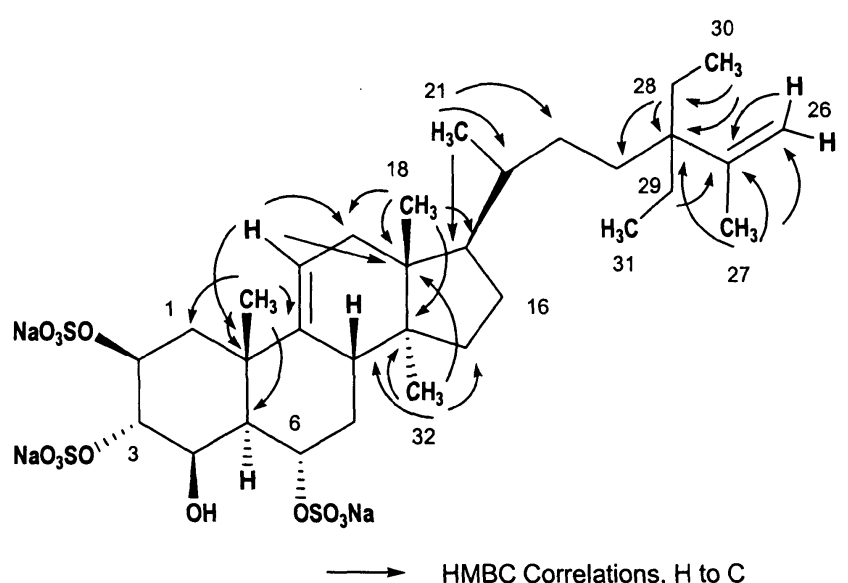

$\mathrm{H}-\mathrm{C}$ long range correlations from a HMBC spectrum. Observation of long range ${ }^{1} \mathrm{H}_{-}{ }^{13} \mathrm{C}$ correlations of $\mathrm{H}_{3}-27(\delta$ $1.64)$ to $\mathrm{C}-24$ ( $\delta 45.7), \mathrm{C}-25$ ( $\delta$ 150.9), and C-26 ( $\delta$ 113.0) allowed us to determine that the vinyl group was in between the methyl group and the quaternary carbon. The two remaining ethyl groups (fragment B) could only be located on the quaternary carbon (C-24). This was confirmed by the long range correlations of $\mathrm{H}_{2}-28, \mathrm{H}_{2}-29(\delta 1.37), \mathrm{H}_{3}-30$ $(\delta 0.68)$ and $\mathrm{H}_{3}-31(\delta 0.69)$ to $\mathrm{C}-24(\delta 45.7)$. Eventually, the connection of $\mathrm{C}-23$ and $\mathrm{C}-24$ was determined based on the correlations of $\mathrm{H}_{2}-28, \mathrm{H}_{2}-29$ to $\mathrm{C}-23$ ( $\delta$ 31.4). Therefore the side chain terminal was determined to be 24,24-di-ethyl-25-methyl-25,26-ene.

Three sulfate groups were assigned to $\mathrm{C}-2(\delta 76.1), \mathrm{C}-3$ ( $\delta 76.8)$, and C-6 $(\delta 76.3)$ due to their downfield chemical
Fig. 3. Key NOESY correlations of $\mathbf{1}$

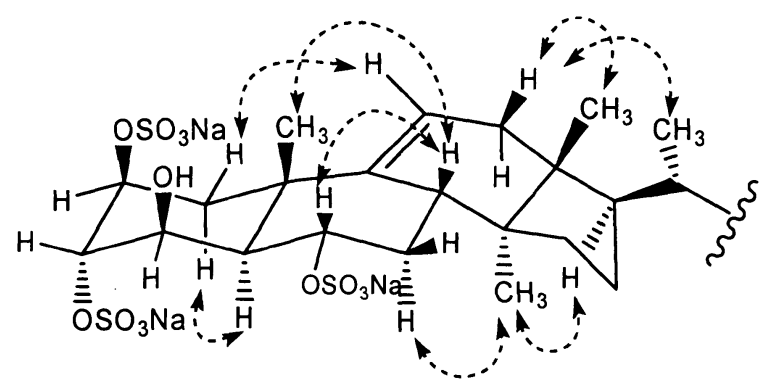

shifts, and these assignments were also supported by ${ }^{13} \mathrm{C}$ data in comparison with those of reported analogues, such as topsentiasterol sulfates. ${ }^{2)}$ Stereochemistry of $\mathbf{1}$ was determined by the ${ }^{1} \mathrm{H}-{ }^{1} \mathrm{H}$ coupling pattern and NOE data. Key NOE Correlations are shown in Figure 3. These data were virtually identical to those of topsentiasterol sulfates. ${ }^{2)}$ Thus, the structure elucidation of $\mathbf{1}$ was completed and shown in Figure 2.

Compound 1 was determined as a new sterol sulfate having a rare side chain which has di-ethyl substitution on $\mathrm{C}-24$. To the best of our knowledge, this is the first marine sterol to possess such a side chain. In the plant kingdom, only laureolol and its 3-O-methyl analogue possess this side chain. ${ }^{3,4)}$

Compound 1 exhibited antifungal activity with MIC $15 \mu \mathrm{g} / \mathrm{ml}$ against supersensitive Saccharomyces cerevisiae PM503, a modification strain of wild-type $S$. cerevisiae in which two efflux pumps, a gene involved in sterol metabolism and a chitin synthetase gene have been disrupted. Standard compound posaconazole gave MIC of $4 \mathrm{ng} / \mathrm{ml}$ when tested under the same conditions. No activity was observed at $60 \mu \mathrm{g} / \mathrm{ml}$ against $S$. aureus, C. albicans, and E. coli.

\section{Acknowledgement}

The authors wish to thank JOSEPH COLBY for assistance with the NMR instrumentation.

\section{References and Notes}

1) Hartman, W. D.: New genera and species of coralline sponges (Porifera) from Jamaica. Postilla 137: 1 39, 1969

2) Fusetani, N.; M. Takahashi \& S. Matsunaga: Topsentiasterol sulfates, antimicrobial sterol sulfates 
from a marine sponge, Topsentia sp. Tetrahedron 50: 7765 7770, 1994

3) ZHANG, H.-J.; X.-F. GAO \& M.-Z. ZHANG: $O$ Methyllaureolol from Skimmia laureola. Chin. Chem. Lett. 6: 873 874, 1995
4) Zhang, H.-J.; M.-Z. ZhANG \& X.-F. GAO: Structure determination of $O$-methyllaureolol from Skimmia laureolas sp. Multinervia by 2D HMQC and HMBC techniques. Mag. Res. Chem. 35: 410 413, 1997 